\title{
Treatment of sexual dysfunctions: psychological principles and approaches (Part II)
}

\author{
Kapila Ranasinghe ${ }^{1}$ \\ Sri Lanka Journal of Obstetrics and Gynaecology 2009; 31: 122-124
}

Key words: Sexual dysfunction, psychological approaches, psychological principles

\section{Psychological treatments; current paradigms and techniques}

There is a large literature on the psychological approaches to the treatment of sexual dysfunction. Many authorities still feel psychological therapy as one main component treatment when help is sought for sexual dysfunction, although obviously there are instances where a physical approach might be more appropriate.

Psychological therapies are of different forms.

\section{a) Anxiety Reduction and Desensitization}

Anxiety reduction is often taught to the patients at an early stage. This can be done by many means. Simple life style changes and regular exercises are helpful for people who lead very stressful lifestyles. The commonly used approach of proscribing sexual activities at the beginning of the therapy itself reduces the performance anxiety of many sufferers. This can be easily augmented with the non demanding body pleasuring activities like sensate focus. A small number of couples or individuals may need specific relaxation exercises.

\section{b) Behavioural therapies}

The more widely used psychological therapies for sexual dysfunction are best described as behavioural, although in recent years cognitive approaches have also been added. In the behavioural approach, the treatment is directed toward the sexual problem itself. A major element of this is the reduction of anxiety, as in most cases anxiety acts as a factor that perpetuates the dysfunction. The more one fails in sex, the more anxious one gets. One also tends to become a 'spectator' of one's own performance, thus inhibiting spontaneous sexual responses and sexual enjoyment. Hence, in therapy the reduction of anxiety

${ }^{1}$ Consultant Psychiatrist, National Institute of Mental Health, Angoda, Sri Lanka.

E-mail: kapila_ranasinghe@hotmail.com becomes a major priority. Early behaviour therapists for example, Joseph Wolpe used this approach for the treatment of sexual problems. This basic behavioural approach was followed by a more formal, treatment package developed by William Masters and Virginia Johnson-universally known as the 'Masters and Johnson approach'1. In this, after the assessment, the couples are asked to agree to proscribe on intercourse, and are given detailed instructions in graded sexual exercises. The is initially recommended non genital pleasurable (non genital sensate focus) and when they master it they can go on to practise genital pleasurable activities called genital sensate focus exercises.

Non genital sensate focus exercises:

- The couple is given much reinforcement to lessen anxiety and their attention is taken away from genital sex.

- The couple starts touching and caressing, excluding the genital areas and the woman's breasts

- They are urged to use fantasies to distract them from obsessive concerns about performance, which is termed spectatoring.

- Couple is encouraged to give and receive bodily pleasure without the pressure of performance.

- Beginning exercises usually focus on heightening sensory awareness to touch, sight, sound, and smell.

- Nowadays can also be done as a sensual massage technique on each other.

- The needs of both the dysfunctional partner and the non dysfunctional partner are considered.

Genital sensate focus exercises:

- Genital stimulation is eventually added to general body stimulation.

- This is usually done as a form of mutual masturbation.

- If either partner becomes sexually excited by the exercises, the other is encouraged to bring him or her to orgasm by manual or oral means. 
- This procedure is important to keep the non dysfunctional partner from sabotaging the treatment.

- The couple is sequentially taught to try various positions for intercourse without necessarily completing the act and to use varieties of stimulating techniques before they are permitted to proceed with intercourse.

After some practice sessions of this, which the couple carries out at home, they move on to the specific additional behavioural strategies used to deal with the specific problems the couple has presented with.

Examples are the 'squeeze' technique for premature ejaculation, 'overstimulation' for retarded ejaculation, and use of graded dilators for the treatment of vaginismus. In erectile difficulties, a 'teasing' approach may be used, enabling the male to learn to defocus on the erection and relinquish control.

The principles of the Masters and Johnson approach can also be used with patients who do not have partners, with certain modifications. In the early stages, they are usually asked to engage in 'selffocusing'.

\section{c) Cognitive behavioural therapy}

In the practice of psychological therapy, behavioural and cognitive elements are often used in conjunction, hence the term 'cognitive- behavioural therapy used by many therapists. In practice behavioural approach is often augmented by cognitive interventions. Cognitive techniques are particularly applicable for those without partners, who tend to avoid developing relationships because of fear of repeated failure. This involves identifying faulty or dysfunctional cognitions that the patient may have. Such dysfunctional cognitions (thoughts, beliefs, and attitudes) are often major factors in the aetiology and, more commonly, of the perpetuation of sexual dysfunctions. They include cognitions such as 'I am sure to fail again', 'If I do not get an erection, my partner will ridicule me', and 'It is going to be painful again'. The therapist elicits such cognitions from the patient as part of the assessment, and then works on modifying these, using techniques of cognitive therapy.

In recent years, the psychological approach has been expanded to include a systemic dimension. The sexual dysfunction is viewed in the context of the overall relationship of the couple. Relationship factors such as jealousy, resentment and dominance often contribute to the sexual problems. The therapist takes these into account and intervenes appropriately. These systemic interventions are undertaken within the context of an overall behavioural framework. There is evidence that this expanded approach is rapidly gaining popularity among therapists who specialize in the psychological treatment of sexual dysfunction ${ }^{2}$.

\section{d) Group setting}

This is rarely done nowadays. However group approaches are used in countries where sexual issues can be discussed without prejudice. Therapists sometimes run groups for patients without partners, or even see couples in groups. In these, much cognitive work is done in the group setting and, in addition, behavioural exercises are discussed and outlined.

The original Masters and Johnson approach always used a team of two therapists, one male and one female, with every couple. In the practice of sexual dysfunction therapy today, this is the exception rather than the rule. In most instances, one therapist sees the couple, or the individual who has no partner.

\section{e) Psychodynamic therapy}

Psychodynamic therapy aims to understand the presenting problem as a manifestation of an underlying, unconscious conflict or memory, and it is often assumed that this has its origins in childhood. The therapy takes the form of a verbal, interactive endeavour, which also uses transference (emotional responses of the patient to the therapist) as a means of resolving problems. Psychodynamic therapy for sexual dysfunction has not been adequately evaluated. There is a practical problem, too, in that such therapy is time-consuming. However, there are circumstances when such an approach may be appropriate.

\section{Outcome of psychological therapy}

The very high success rates reported by Masters and Johnson and Kolodny et al. have not been matched by later investigators ${ }^{1,3}$ but there is, generally, evidence that the cognitive behavioural approach is beneficial to many patients ${ }^{4,5,6}$.

A thorough evaluation of the outcome of sex therapy is not easy to undertake because of various confounding factors, such as heterogeneity of samples, lack of uniformity in outcome measures, ambiguity of criteria of improvement, preponderance of single case reports, poor description of patient characteristics, absence of data on drop-outs and failures, and so on ${ }^{7}$. Within these limitations, the available data are encouraging. There are no reliable comparative 
outcome data but, on the whole, $50 \%-60 \%$ of couples who enter treatment show a satisfactory outcome.

A related issue is that of the mechanisms of change. Even when various techniques and strategies achieve clinical success, the mechanisms through which change has been achieved is not always clear. Bancroft has highlighted this issue and offered a valuable, discussion ${ }^{5}$. The relative lack of understanding of mechanisms of change also reflects the uncertainty about the aetiological factors in these dysfunctions.

The outcome literature also points to factors associated with prognosis. Good prognostic factors include the quality of the overall relationship and absence of external factors that weaken the relationship. Motivation for therapy also appears to be a key factor. There is also some evidence that the attractiveness of the partners to each other predicts a satisfactory outcome. Current psychiatric illness and is a predictor of poor outcome.

\section{References}

1. Masters WH, Johnson VE (1970). Human sexual inadequacy. Boston: Little Brown.

2. Crowe M. Couple therapy for sexual dysfunction. International Review of Psychiatry 1995; 7: 195-204.

3. Kolodny RC, Masters WH, Johnson VE. A textbook of sexual medicine. 1979 Boston: Little Brown.

4. Bancroft J. Human sexuality and its problems. 2nd ed. 1989 Edinburgh, UK: Churchill Livingstone.

5. Bancroft J. Sexual problems. In: Clark DM, Fairburn CG (eds). 1997, Science and 6Hawton K, Catalan J, Martin P, et al. Long-term outcome of sex therapy. Behaviour Research and Therapy 1986; 24: 377-85.

6. Hawton K, Catalan J, Martin P, et al. Long-term outcome of sex therapy. Behaviour Research and Therapy 1986; 24: 377-85.

7. Beck JG. Behavioural approaches to sexual dysfunction. In: Turner SM, Calhoun KS, Adams HE (eds). 1992, Handbook of clinical behaviour therapy. 2nd ed. New York: Wiley. 